Article

\title{
Sequencing Infrastructure Investments under Deep Uncertainty Using Real Options Analysis
}

\author{
Nishtha Manocha * and Vladan Babovic \\ Department of Civil and Environmental Engineering, National University of Singapore, \\ Singapore 117576, Singapore; vladan@nus.edu.sg \\ * Correspondence: nishtha.m@u.nus.edu
}

Received: 8 January 2018; Accepted: 12 February 2018; Published: 23 February 2018

\begin{abstract}
The adaptation tipping point and adaptation pathway approach developed to make decisions under deep uncertainty do not shed light on which among the multiple available pathways should be chosen as the preferred pathway. This creates the need to extend these approaches by means of suitable tools that can help sequence actions and subsequently enable the outlining of relevant policies. This paper presents two sequencing approaches, namely, the "Build to Target" and "Build Up" approach, to aid in sub-selecting a set of preferred pathways. Both approaches differ in the levels of flexibility they offer. They are exemplified by means of two case studies wherein the Net Present Valuation and the Real Options Analysis are employed as selection criterions. The results demonstrate the benefit of these two approaches when used in conjunction with the adaptation pathways and show how the pathways selected by means of a Build to Target approach generally have a value greater than, or at least the same as, the pathways selected by the Build Up approach. Further, this paper also demonstrates the capacity of Real Options to quantify and capture the economic value of flexibility, which cannot be done by traditional valuation approaches such as Net Present Valuation.
\end{abstract}

Keywords: deep uncertainty; Real Options Analysis; sequencing approaches

\section{Introduction}

Policymakers today are faced with the difficult task of planning for large-scale infrastructure that can cater to the climatic and socio-economic changes that the future will bring. Large-scale infrastructure is cost intensive, has a life span of at least a few decades, requires long-term planning and is essentially irreversible. Thus, when built as a strategy to cope with a changing climate, infrastructure systems carry an inherent risk. Given the inability to accurately predict the future, infrastructure systems designed and commissioned by employing the "predict then build" approach could fail to meet their objectives if the future turns out to be incompatible with the future initially assumed in the design stage. Therefore, to address this deeply uncertain nature resulting from long-term changes, it is becoming necessary to develop strategies and plans that support flexibility and react more strategically than traditional planning approaches, i.e., identify strategies that perform well under many future scenarios, instead of optimizing a strategy for only a handful [1].

Urban water infrastructure development requires careful long-term planning to reduce the risk of climate change and other uncertainties [2] such as population growth, economic development, urbanization, and a changing social and political environment, etc. In response to this, various approaches have been developed over the years to aid decision makers' in this regard. These are Assumption-based Planning [3,4], Robust Decision Making [5,6], Decision Tree Analysis [7], Adaptive Policy Making [8,9], Adaptation Tipping Point [10-12], Adaptation Pathways [11,13], Dynamic Adaptation Policy Pathways [14,15], Info Gap Robustness Pathway Method [16] and Real Options analysis [17-20]. In addition, there are many other methodologies, tools and techniques that support 
these approaches. A few examples are: scenario planning [21], assumption-based planning [3], Monte Carlo Analysis [17], Exploratory Modeling Analysis [22] and Info gap decision theory [23]. Among these approaches, the adaptation tipping point and adaptation pathway approach $[11,13]$ are increasingly gaining popularity in view of climate change adaptation.

Adaptation Pathways provide decision makers with an excellent overview of all available actions and possible sequences and combinations that can be made to ensure that the system performs as expected in its lifetime. While this broad overview is very beneficial, it still leaves decision makers with the dilemma of which particular action should be exercised today, which action should be exercised with a delay and which action should be kept as an option. Studies [11] have suggested that the weakness in the adaptation pathway approach is the complexity of the analysis and any simplifications that must be made to make the analysis tractable. Therefore, in order to answer these questions, it becomes necessary to analyse these pathways in greater depth with suitable tools. Further assessment has to be carried out to enable the sub-selection of a set of preferred pathways. This is necessary as decision makers have to outline a plan(s) that will be followed given that the climate changes as expected and to identify policies that have to be implemented both in the short and long term. Pathways that are not selected in the current time frame remain active as options in case the future turns out to be incompatible with selected plans.

The subselection of the pathways can be undertaken in a few different ways depending upon the viewpoints of the management, the data available and the trust or preference in one methodology over the other. The case studies presented in this paper illustrate adaptation pathway maps for flood management. The first case study, the Kent Ridge Case [24] Study, is focused on flood management for a small tropical urban catchment located in Singapore, while the second is a hypothetical case study focused on flood management for the Rhine delta [3]. The first case study presents a basic economic assessment to rank the various adaptation pathways and presents the best performing (economically) adaptation pathways as the preferred subset. Subsequent studies on the Waas Case [15] aim to use multiobjective robust optimization to trim down the solution space. This paper uses these two case studies to explore and provide an alternative approach to improve the manner in which the adaptation pathways are shortlisted. This is done by employing two formal sequencing approaches to outline the preferred set of adaptation pathway(s).

Sequencing approaches have been used for a long time to identify long term plans for infrastructure development. In the context of water resources, management sequencing has been used extensively to identify water supply projects [24]. These include studies that focus on reservoir expansion [25-27], groundwater supply [2] and building a water supply portfolio [28-30]. In these studies, the economic cost calculated by means of traditional Net Present Valuation is used as the primary parameter to guide the sequencing. However, traditional valuation approaches including the Net Present Value (NPV) are inherently flawed in analyses projects with future uncertainties [31]. A real options valuation is a more appropriate tool for decision making under uncertainty. The ability to adapt a solution at a time in the future when more information about the uncertain driver is available allows one to limit the downside of making a wrong decision, and capture the upside of new information and opportunities. This flexibility can be translated into an economic gain which can be captured by Real Options Analysis. Real Options Analysis has previously been used to support decision making under deep uncertainty in a handful of case studies. In the area of infrastructure design and management, applications include analyzing scale versus flexibility [32], architecting a maritime domain protection system [33,34], design of a parking garage [35], design of urban water management systems [20], flood risk management [18,36,37] and design of water supply systems [17]. The objectives of this paper are to:

- Present two formal sequencing approaches to extend the current adaptation tipping point and adaptive pathway approached. These include the 'build up' (BU) and 'build to target' (BTT) approaches [38]. The purpose of the sequencing exercise is to identify a preferred pathway(s) that will be followed given that the climate changes as expected. Given the nature of the adaptive 
approach, the pathway(s) can be supplemented or updated if the manifestation of reality is other than what was planned for.

- To demonstrate the ability of these approaches by applying them to two case studies in the domain of flood management.

- To assess the impact of choosing different selection criterions (Net Present Value and the Real Options Analysis) on the performance of these approaches and the subsequent sub-selection of the adaptation pathway(s).

- To understand if different perspectives of national development (varied landuse) can have an impact on the economic performance and the shortlisting of the various pathways. This objective is specific to the Kent Ridge Case Study.

The rest of the paper is organized as follows: The overall framework used in this paper is presented in Section 2. The sequencing approaches and the steps involved in using these approaches to extend the adaptation tipping point and the adaptation pathway approach are explained in detail in Section 3. The two case studies are described in Section 4, following which the results are presented and discussed in Section 5. Finally, a summary of the paper is presented in Section 6.

\section{Methodology}

The sequencing approaches presented in this paper are employed to enable the selection of a subset of preferred pathways once the adaptation pathway maps are available. In the development of adaptation pathway maps, the first step is the description of the case study and the outlining of the current situation in order to better understand the objectives. The second step is the identification and development of a portfolio of adaptation actions that can be implemented to ensure that objectives are met all along the planning horizon. The next step is the definition of scenarios, over which the adaptation actions will be assessed. The fourth step is the setup an assessment model. Thereafter, the tipping points of the adaptation actions in isolation and combination are calculated.

Adaptation Tipping Points are the physical boundary conditions where acceptable technical, environmental, societal or economic standards may be compromised [9]. Once determined, the tipping points are positioned in time using the assessment scenarios and are combined to draw the adaptation pathway maps. This approach is illustrated in Steps 1 through 5 of Figure 1. A combination of the defined Adaptation Tipping Points with assessment scenarios used to develop adaptation pathway maps provides information on the resilience of the infrastructure system to climate change and the potential need for alternative adaptive strategies.

The complete framework employed in this study is presented in Figure 1. Steps 1 through 5 are part of the adaptation tipping point and the adaptation pathway approach presented in previous studies [13,39]; Step 6 is presented in this paper.

The proposed sequencing approaches employed in this paper involve dividing the pathway into a number of phases $(\mathrm{P})$ wherein adaptation actions have to be implemented. A pathway is composed of a set of adaptation actions that meet the study objectives all along the planning horizon (T). The numbers of phases that each pathway has are dependent upon the timing of reaching the adaptation tipping point of the individual adaptation actions involved in the pathway. That is, once an adaptation tipping point is reached, a new phase of investments is required that can add another adaptation action to the current configuration.

The purpose of both of the sequencing process is to identify the combination of adaptation actions at the beginning of each phase so as to maximize the selection criterion while meeting the study objectives.

In order to perform the sequencing based on the two approaches, identify the preferred pathway and compare the two sequencing processes, two economic selection criterions were identified. These are the net present valuation (NPV) and real option assessment (ROA). The sequencing was performed individually for each of these selection criterions to compare the impact of using different selection 
criterions on the sequencing approaches. A higher value of the selection criterion indicates a better economic performance of the pathway.

Net Present Valuation is the traditional approach for making investment decisions. The NPV approach applies a discount rate calculated either by the opportunity cost, the weighted average cost of capital or other methods to represent all future cash flows in present equivalent economic units. By discounting both the future costs and benefits to the present time, it tries to estimate whether the project's cost can be offset by the expected benefits. The investment rule is to investigate when NPV is greater or equal to zero. For mutually exclusive projects, the rule is to choose the project with the highest NPV. In contrast to this, the Real Options analysis is a relatively new approach that is now gaining traction in the valuation of flexible adaptive investments that must be made under deep uncertainty. Real Options Analysis is able to take into account and value uncertainty and flexibility; as opposed to traditional approaches of economic valuation borrowing concepts originating from the options analysis developed in finance [40], we can apply them to undertake a Real Options Analysis for management of infrastructure systems [33]. The specifics of performing a real options analysis are beyond the scope of this paper. For details on how to perform this assessment, please refer to [31].

Step 1: Description of case study and Study Objectives.

Step 2: Definition of adaptation actions

Step 3: Development of assessment scenarios

Step 4: Setup of assessment model

Step 5: Calculation of adaptation tipping points and building of adaptation pathway maps

Step 6: Evaluation and sub selection of developed adaptation pathways by sequencing approaches

Figure 1. Overall framework of the study.

\section{Sequencing Approaches}

In the Build Up (BU) method, the adaptation pathway is identified in a chronological order. Decisions on the adaptation action that has to be implemented are made for one phase at a time. Once a decision about a specific phase is made, the concerned adaptation action is built and remains fixed for the entire planning horizon. By contrast, in the Build to Target (BTT) method, the pathway to be built is selected by maximizing the value of the selection criterion for the final year of the planning horizon. Once the pathway is identified, the individual adaptation actions that make up the pathway are built based on encountering their respective tipping points in reality.

This can be better understood by considering a simple example. Let us say that we have to design a water supply portfolio that can cater to the water demand of a town, by supplying it with " $X$ " liters per day of water in the year 2100. In order to do this, let us assume that the town has a few different adaptation actions it can consider. These include: expanding the water reservoirs to increase storage capacity, building desalinization plants, increasing the domestic rain water harvesting capacity and constructing water recycling facilities. If we approach this problem by the BTT method, we will run simulation models and find the best set of actions, or the best pathway (based on governance perspective, for example, a solution that performs the best economically; technically, the most energy 
efficient) that can collectively supply the town with " $\mathrm{S}$ " liters of water in the year 2100 . Let us assume that this best pathway includes increasing the reservoir storage capacity by $30 \%$ and having a desalination plant of capacity " $X$ " liters/day. Once this pathway is selected, the timing of bringing these adaptation actions online can be selected by means of assessing the adaptation tipping points (time when a given configuration has a supply lower than the demand) under various user defined scenarios. The timing of implementing the individual adaptation actions can be revisited in the future when more data about the uncertainty driver are available. However, if the same decision is to be made by the BU approach, the decision is taken in phases. The system is first assessed to find the tipping point of the current configuration. Let us assume that the current configuration can supply the town with water until the year 2030. Thus, we now need to identify the particular adaptation action that should be implemented by 2030 to ensure that the town has sufficient water to meet its needs. We do so by running simulations and finding the best suited adaptation action to be implemented in the next phase. Let us assume that the simulations result advocates the increase of domestic rain water harvesting schemes of capacity " $Y$ " liters which have a tipping point in the year 2060. As our planning horizon stretches to the year 2100, we have to identify the adaptation action that has to be implemented in the subsequent phase. In this case, the adaptation action identified is building a desalinization plant of capacity " $Z$ " liters/day which has a tipping point in the year 2105. Thus, the pathway identified by the BU approach is implementing a domestic rain water harvesting scheme of capacity " $Y$ " liters by the year 2030 and bringing online a desalinization plant of capacity " $Z$ " liters/day by the year 2060 .

Given the nature of the BTT approach, since the adaptation pathway is identified first, even though the timing of building each phase carries some flexibility, the action to be built at each phase is constricted to align with the selected pathway. In this regard, the Build Up method is more flexible and capable to respond to future changes, such as a changing climate, changing population, changing landuse, etc. However, it also generally results in less favorable selection criterion values compared with those obtained using the Build to Target method for the selected design conditions, which are a disadvantage if the assumed design conditions actually occur [41]. The following sub-sections shed light on the steps involved in performing each sequencing technique.

\subsection{Build to Target (BTT) Method}

The proposed process of sequencing using the BTT method is shown in Figure 2. The first step is identifying the measures, policies or adaptation actions already in place to meet the study objectives. Subsequently, the pathways developed are ranked based on their selection criterion performance. The pathway that meets the study objectives for the whole planning horizon and also maximizes the selection criterion is chosen as the preferred pathway. Consequently, based on how reality unfolds, the individual actions that make up the pathway phases are built.

\subsection{Build Up (BU) Method}

The proposed process of using the Build Up (BU) method is shown in Figure 3. The first step is identifying the measures, policies or adaptation actions already in place to meet the study objectives. Following this, the actions to be implemented in the next phases are identified. This identification is based on the average value of the selection criterion of the phase in consideration across the range of assessment scenarios. The value of the selection criterion is maximized at each phase. This is repeated until the identified actions in combination can cater to the entire planning horizon, i.e., have an adaptation tipping point (ATP) greater than or equal to the final year of the planning horizon (T). 
Identify list of current active adaption actions

Select the combination of active and available adaption actions that maximize the selection criterion value across the assessment scenario along the entire planning horizion $\mathrm{T}$.

Identify the adaption actions for each phase in accordance with the selected pathway.



Output preffered pathway

Figure 2. Build to Target (BTT) sequencing approach. 


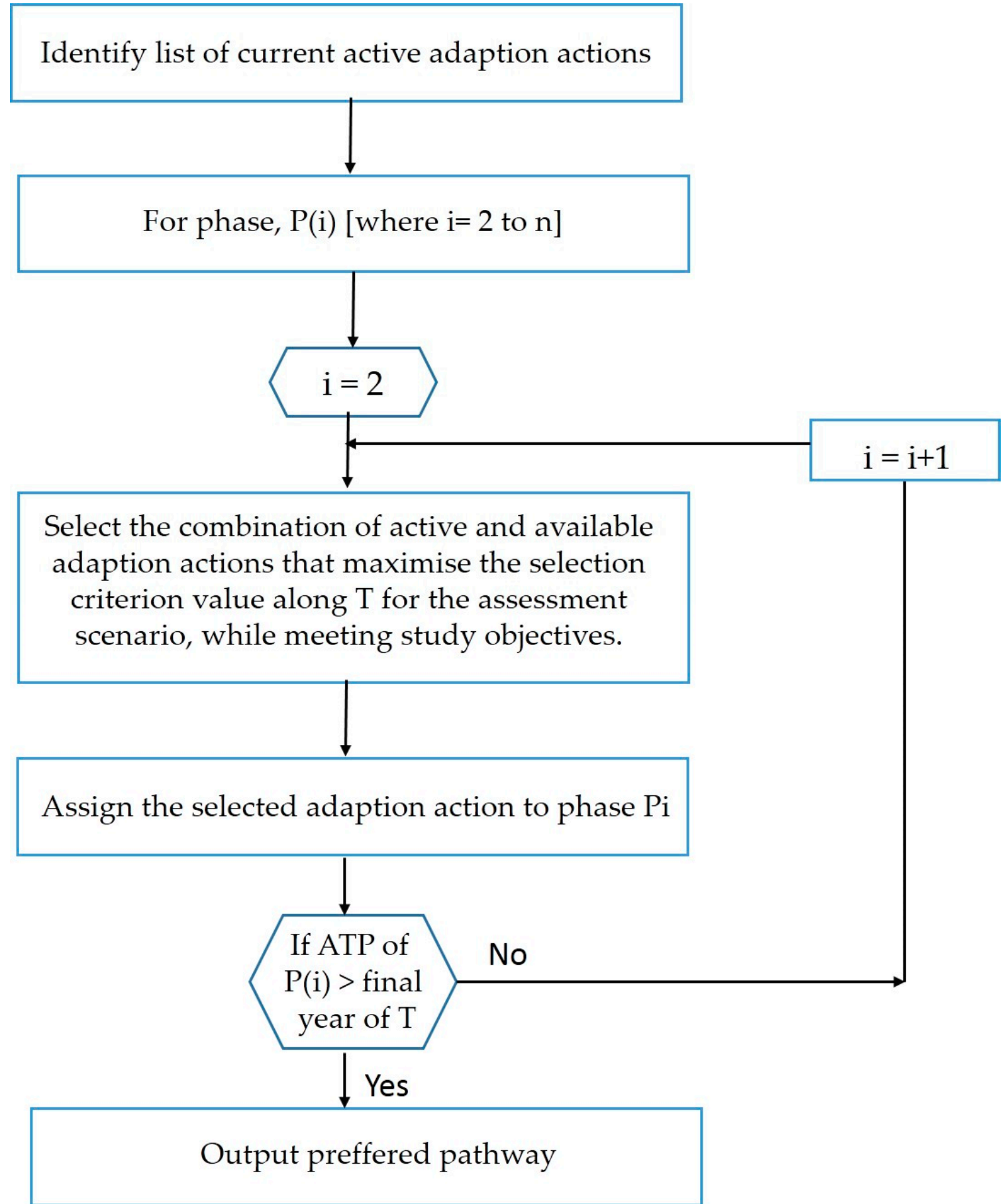

Figure 3. BU Sequencing approach.

\section{Description of Case Studies}

Two case studies are employed in this paper to present the sequencing approaches. The two case studies are focused on flood management but differ in size and geographical location. This section introduces the two case studies and provides the necessary background information on the same in the context of this paper. 


\subsection{Kent Ridge Catchment}

The Kent Ridge Catchment is a tropical urban catchment located in the south of Singapore. The Kent Ridge Catchment is 85,000 square meters in size and is located within the campus of the National University of Singapore. This catchment contains all the main land use types of Singapore and hence can be considered as reasonably representative from a hydrological point of view.

The adaptation tipping point and the adaptation pathway approach were employed in a previous study [39] to develop adaptive plans for flood management in the Kent Ridge Catchment. The adaptation actions and assessment scenarios explored have been presented here for brevity. For details, please refer to the original study.

The adaptation actions considered in this study are defined in terms of infrastructure that can be built or modified for the purpose of storm water management for dense urban areas. The portfolio of actions includes both traditional grey and innovative green infrastructure solutions, namely: expansion of drainage canals, implementation of green roofs and implementation of porous pavements. The adaptation actions encompass a drainage increase in four configurations (C1-C4), implementation of porous pavements in three configurations (C1-C3) and the implementation of green roofs in three configurations (C1-C3). Further, the actions explored are aligned with the national objectives of Singapore. These actions, in varied configurations, make up the set of adaptation actions assessed in this study. They are described and summarized in Table 1 . The notations specified in Table 1 are used to address the actions in the subsequent sections of this paper.

Table 1. Portfolio of Adaptation Actions, Kent Ridge case study (Table adapted from [39]).

\begin{tabular}{ccc}
\hline Configuration & Notation & Description \\
\hline Current Drainage Configuration & A & The current configuration is maintained \\
Drainage Increase C1 & B & $15 \%$ increase from baseline drainage capacity \\
Drainage Increase C2 & C & $20 \%$ increase from baseline drainage capacity \\
Drainage Increase C3 & D & $30 \%$ increase from baseline drainage capacity \\
Drainage Increase C4 & E & $50 \%$ increase from baseline drainage capacity \\
Porous Pavements C1 & F & $50 \%$ of all available pavements covered \\
Porous Pavements C2 & G & $60 \%$ of all available pavements covered \\
Porous Pavements C3 & H & $80 \%$ of all available pavements covered \\
Green Roofs C1 & I & $20 \%$ of all available roof space covered \\
Green Roofs C2 & J & $35 \%$ of all available roof space covered \\
Green Roofs C3 & K & $50 \%$ of all available roof space covered \\
\hline
\end{tabular}

The scenarios developed for the Kent Ridge Catchment cover a range of possible climatic (Table S1) and land-use futures (Table S2). This is done to study the individual and coupled impact of climatic and anthropogenic influences on the timing of reaching the respective tipping points. The climatic scenarios include the Wet 1 (W1), Wet 2 (W2) and the Dry 1 (D1) climate scenario. In addition to the climate scenarios described, an additional scenario, namely the "All climate scenario" is presented in the results section. This scenario warrants the running of the sequencing process across the three climate scenarios described in Table S1 and maximizing the mean of the selection criterion across these climate scenarios. The current climate is indicated as Business as Usual (BAU).

The landuse scenarios include a Baseline (landuse B), Green (landuse G) and Sustainable Grey landuse SG) landuse scenario. The baseline scenario is representative of the existing practices of land use. The green scenario follows a sustainable approach. The sustainable grey landuse allows for construction of buildings on account of green spaces but mandates retrofitting the developments in a predefined proportion with storm water management solutions such as green roofs and/or porous pavements.

The adaptation tipping points are described in terms of maximum annual rainfall beyond which the given adaptation action ceases to perform as expected (Figure S1) Using the adaptation tipping points, an adaptation pathway map was developed for the Kent Ridge Catchement. 
Figure 4 can be read like a map indicating several possible routes (adaptation pathways) to reach a desired point (year 2100) in the future. Each adaptation action (shown on the $\mathrm{Y}$ axis) is depicted by a specific color. The $X$ axis represents the ATPs and the corresponding years they are exercised under different climate scenarios. The squares represent interchange points, where one can switch to a different adaptation action. The color of the square indicates the action from which one has to switch. The black bars mean that an ATP is reached and that the current configuration can no longer perform as expected, requiring a switch. Each pathway is defined by the particular sequencing of actions that allows the configuration to meet objectives until the year 2100.

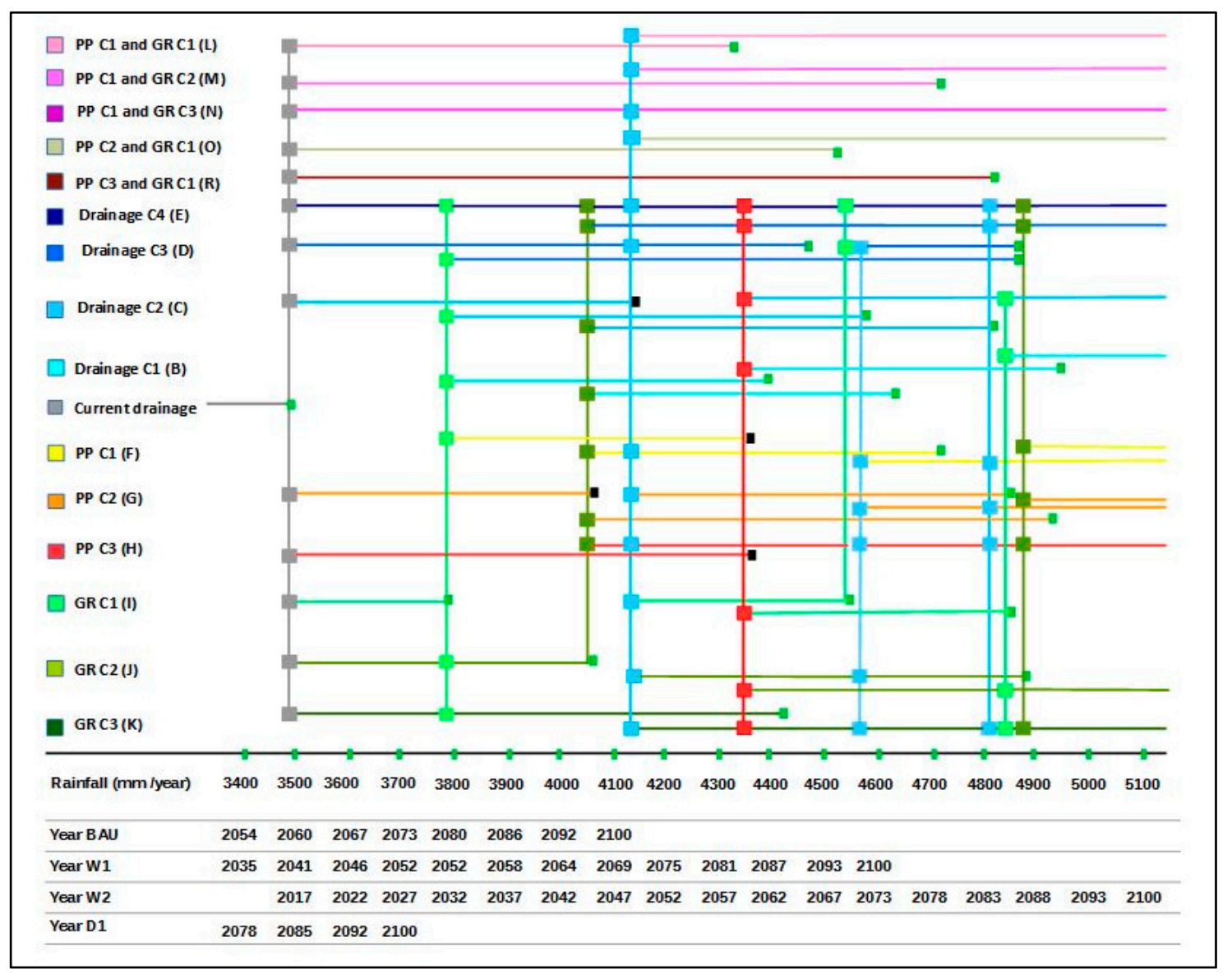

Figure 4. Adaptation Pathways Map, for the current land use and all climate scenarios. Porous Pavements are abbreviated as PP and green roofs are abbreviated as GR. Adapted from [39].

\subsection{The Waas Case Study}

In response to two flood events of the last 30 years that resulted in a total damage of 2810 billion Euros, a hypothetical Waas case study [11] employed the adaptation tipping point and adaptation pathway approach to develop different flood management solutions in the Rhine delta of the Netherlands. The study generated 30 transient scenarios on the basis of three climate scenarios established by the Royal Dutch Meteorological Institute (KNMI). Namely, the "No Climate Change" scenario, the "G" scenario, and the "Wp" scenario [42]. The G scenario has a temperature rise of $1^{\circ} \mathrm{C}$ in 2100 , the winter-time precipitation increasing by $3.6 \%$ and the mean summer precipitation increasing by $2.8 \%$. The $\mathrm{Wp}$ scenario has a temperature rise of $2{ }^{\circ} \mathrm{C}$, winter-time precipitation increasing by $14.2 \%$, but the mean summer-time precipitation decreases by $19 \%$ [42]. In addition to this, the "All" climate scenario was used to depict a central climate scenario. Adaptation actions were defined Table 2 and their respective adaptation tipping points were calculated for all climate scenarios. The portfolio of 
adaptation actions is presented here for brevity (Table 2). Pathways over a time frame of 100 years were then generated. Detailed explanation of the methodology of development of the adaptation pathways is available in the study [11].

While the Waas Case study provided the adaptation tipping points (described as a maximum allowable damage of $200 \mathrm{M}$ Euros) for all adaptation actions under all outlined climate scenarios (Figure S2), it provided one adaptation pathway map drawn for the median adaptation tipping point of all scenarios. In order to facilitate this study, using the adaptation tipping points provided, adaptation maps were developed for the $\mathrm{Wp}, \mathrm{G}$ and No Climate Change scenarios.

Figure 5 can be read like a map indicating several possible routes to get to a desired point (target) in the future. The circles indicate a transfer station to another policy; the blocks indicate a terminal station at which an Adaptation Tipping Point (ATP) is reached. Each adaptation action is indicated by a particular color.

Table 2. Portfolio of Adaptation Actions, Waas case study (Table adapted from [11]).

\begin{tabular}{ccc}
\hline $\begin{array}{c}\text { Configuration } \\
\text { No Policy }\end{array}$ & Notation & Description [11] \\
\hline DH 500 & A & Dike height rise to be able to cope with the 1:500 discharge based on measurements \\
\hline DH 1000 & B & Dike height rise to be able to cope with the 1:1000 discharge based on measurements \\
\hline DH 1.5 & C & Dike rise: adapting to 1.5 times the second highest discharge ever measured ('rule of \\
thumb measure')
\end{tabular}



Figure 5. Adaptation pathway map for flood management based on the median value for the sell-by date of policy options for all climate realizations for the Waas Case adapted from [14].

\section{Results and Discussion}

The adaptation pathway maps in Figures 4 and 5 developed in the case studies described in the previous sections show that in the Kent Ride Case study, assuming a baseline climate, there are 90 possible pathways under the "baseline", 152 possible pathways under the "green" and 245 pathways 
under the "sustainable grey" landuse scenario. For the Waas Case study we have 32 potential pathways that can be employed to cater to the "No Climate Change", 18 potential pathways to cater to "G" and 36 potential pathways to cater to "Wp" climate scenario. As discussed before, while having an overview provided by the adaptation pathway map is beneficial, having so many solutions puts decision makers in a very difficult situation of selecting one from the multiple available pathways for implementation. To make the existing adaptation tipping point and adaptation pathway approaches more suitable to decision making under uncertainty, we thus need to extend the approaches by appropriate tools and techniques. This paper employed two sequencing approaches to enable this subselection of one or a few pathways that can be built to cater to a changing climate.

The results for the two sequencing approaches (Build Up and Build to Target) for the two selection criterions (Net Present Valuation and Real Options Analysis) for both case studies are presented. The sequencing was performed individually for each selection criterion, the Net Present Value (NPV) and the Real Options Value.

In order to read the results of the Kent Ridge Catchment (Figure 6), please refer to the portfolio of available adaptation actions presented in Table 1 and to read those of the Waas Study Figure 7, please refer to the portfolio of available adaptation actions presented in Table 2. Please note, for ease of readability, only a subset of results has been plotted for discussion; tables showing the complete set of results are available in the supplementary material (Tables S3-S10).



Figure 6. Pathways selected for the Sustainable Grey landuse under different climate (C) scenarios, by means of the BTT and BU approach using the Real Options Value and Net Present Value as selection criterions for the Kent Ridge Catchment. 


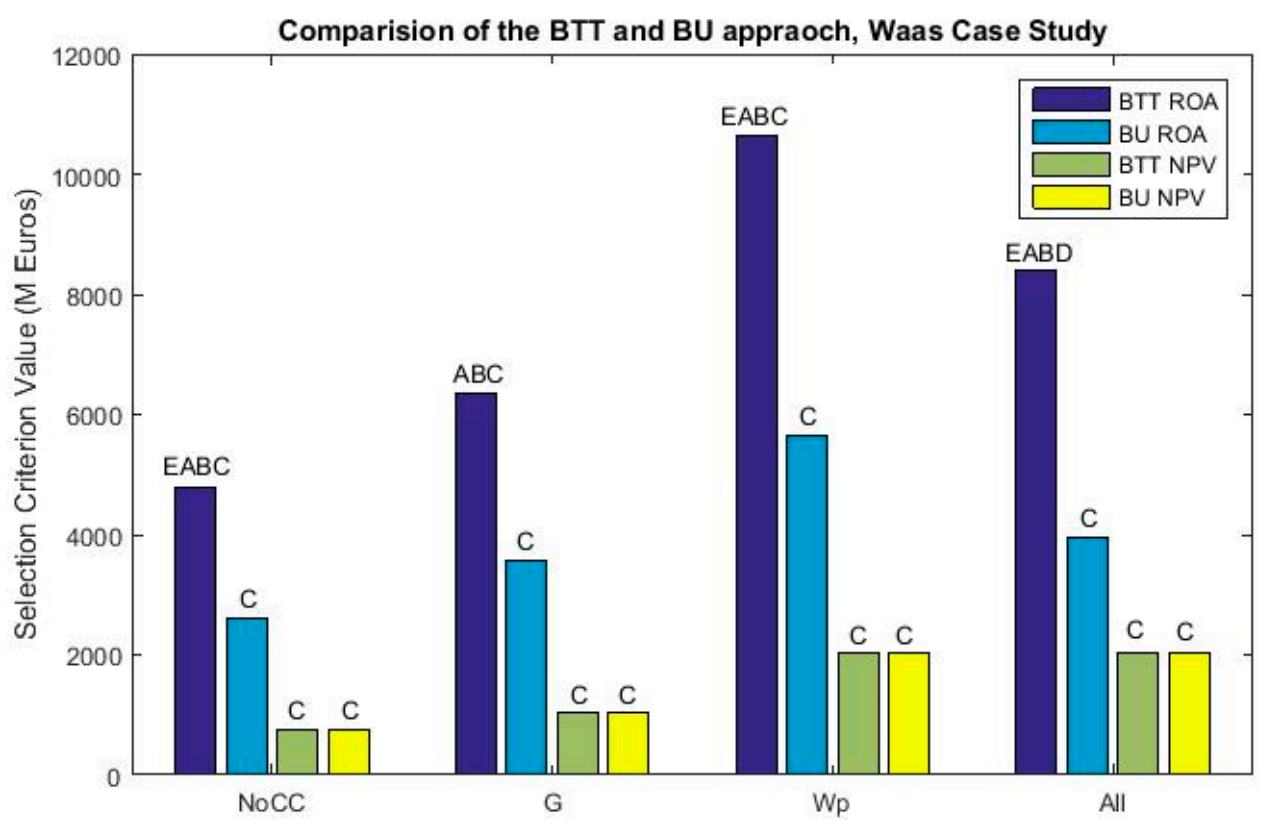

Figure 7. Pathways selected under different climate scenarios, by means of the BTT and BU approach using the Real Options Value and Net Present Value as selection criterions for the Waas Case Study.

Both the Build Up and Build to Target approaches offer different levels of flexibility when used to build and assess adaptation pathways. The Build Up approach lets one start with planning and building for the current or most expected scenario and allows for expanding infrastructure based on the changing climate scenario with time. The selection of the preferred pathway by this approach uses the current state of knowledge as a starting point. It makes current decisions based on what we know today and makes subsequent decisions based on the real future as it unfolds. Although this approach allows easy switching between different climate scenarios, switching to a different climate scenario from this starting point does not lead to building of the pathway that would have been selected if the switched to climate scenario would have been the assessment scenario of choice. The Build to Target approach in contrast warrants the abandoning of a given pathway and revaluating the pathway of choice when dealing with a different assessment scenario at a later time step. The adaptation pathway map developed enables this reassessment to be carried out with relative ease. Thus, while both sequencing approaches help in identification of the preferred pathway, given the characteristic of an adaptation pathway, the identified pathway is not a locked in solution.

Figures 6 and 7 indicate that when comparing the values of the selection criterion of the two approaches, for both case studies it is seen that when Real Options Analysis is the selection criterion of choice, the pathways selected by means of a Build to Target approach generally have a value greater than or the same as that selected by the Build Up approach When NPV is the selection criterion of choice, generally the same pathways are chosen from both approaches. This is due to the nature of the selection criterion.

The traditional NPV assessment misses out on the value of managerial flexibility which is captured and reflected by the Real Options Valuation. This leads to employing only the costs and benefits to maximize the value of the entire pathway (Build to Target) or that of each phase (Build Up) for the entire pathway. Since costs and benefits of each phase are simply added in an NPV assessment, it is expected that an individual action that maximizes the value of the pathway when outlining phases (Build Up) will also be the best candidate when selecting the pathway that maximizes the total value of a given sequence (Build to Target). This once again makes the case for using Real Options Analysis as the selection criterion of choice when making investment decisions under a blanket of uncertainty. Given that the pathway chosen by either approach can be adapted in an unexpected scenario, choosing 
the Build to Target approach upfront is logical as the pathway of choice has a higher (or same) value of the section criterion when compared to the Build Up approach.

The Real Options Assessment criterion assesses the value of a given action as though it was a financial call option. This assessment inherently accounts for the flexibility that is imparted as a result of using a particular adaptation action. On the other hand, the NPV is a standard capital budgeting exercise that justifies the costs of a given pathway against its expected benefits given no flexibility. The higher the value of each of these criterions, the better the pathway is. The preferred pathways based on each of these criterions are different. The selection criterion value of pathways (Figures 8 and 9) suggests that the maximization of one criterion can only be achieved at the compromise of the second. In other words, maximizing flexibility comes at a cost. This is evident by the fact that a higher Real Options Value is accompanied by a drop in the NPV criterion value.

The Kent Ridge case study has an additional study objective of identifying the preferred landuse in addition to the preferred pathway. The pathways developed for the sustainable grey landuse consistently maximize the value of the selection criterion across the entire set of climate scenarios (Figure 10). This result is very interesting for land scarce nations such as Singapore as it indicates that the sustainable grey landuse scenario economically outperforms the other land use scenarios. Thus, the need for storm water management can be met while simultaneously freeing up land area for other purposes.



Figure 8. Comparison of Selection Criterion Values for pathways selected by the BTT sequencing approach under different climate (C) and landuse (L) scenarios, Kent Ridge Catchment. 


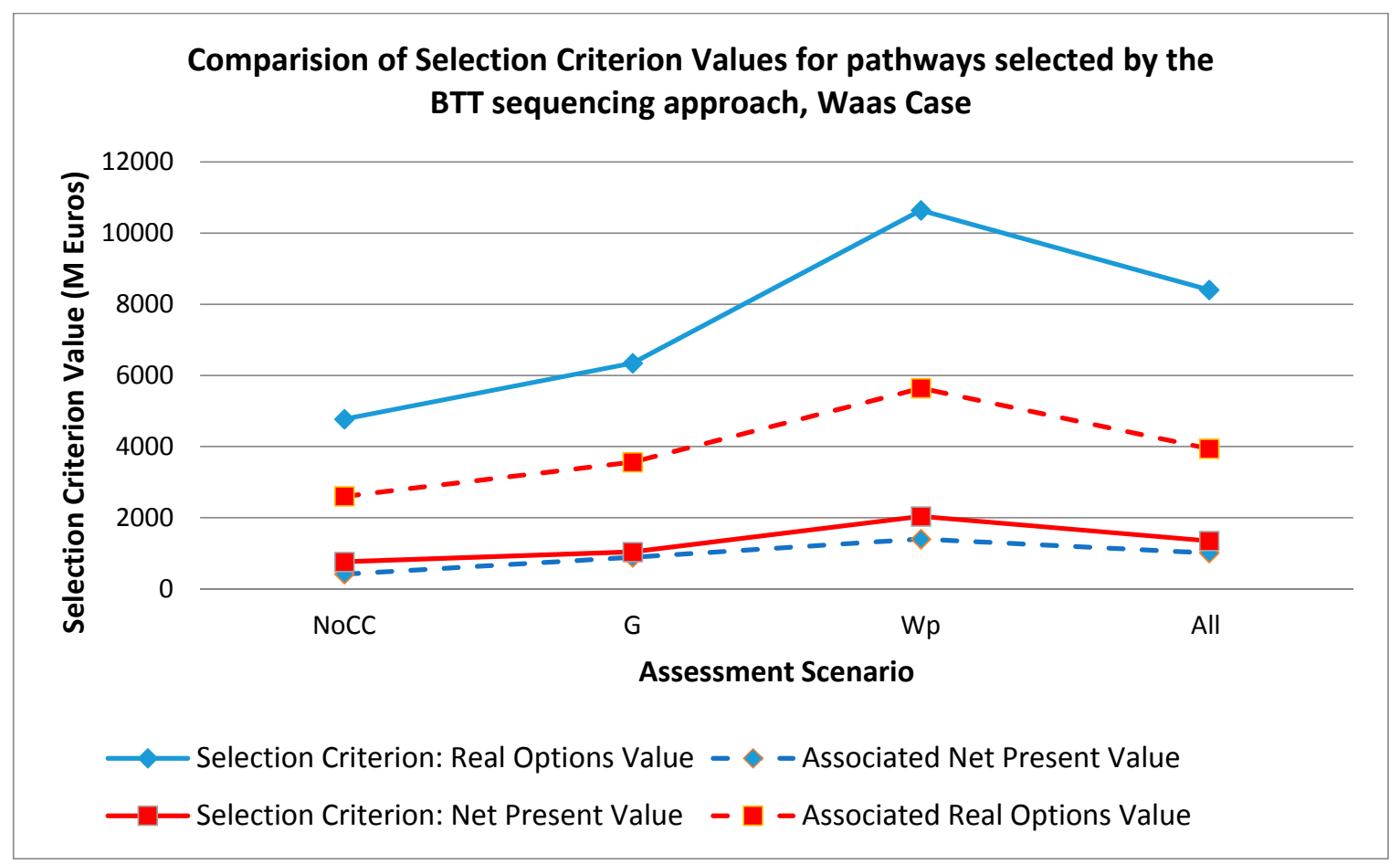

Figure 9. Comparison of Selection Criterion Values for pathways selected by the BTT sequencing approach under different assessment scenarios, Waas Case.



Figure 10. Comparison of the selection criterion (Real Options Analysis) for pathways selected for different climate scenarios (C) and landuse scenarios by the BTT sequencing approach for the Kent Ridge Catchment.

The final question that has to be answered is the selection of the assessment climate scenario for identifying the preferred pathway. For a pathway to be viable for an individual climate assessment scenario, it has to be extendable to adapt to a changing climate if necessary. Thus, if we consider building infrastructure in Kent Ridge to cater to the baseline climate scenario, it is provisioned to 
timely and economically expand to cater to a W1 or W2 climate scenario when necessary. The same reasoning is used when designing pathways for individual climate scenarios for the Waas case study. Thus, the selected adaptation action for any phase of development can be changed to the other actions available in the adaptation pathways map. The change could be triggered by the need to align actions with the national development policies, the priorities of the stakeholders, new technologies improving the economic performance of a given action, changing objectives or even the introduction of new objectives that have to be met along the planning horizon. In both the case studies, the purpose of running the sequencing over the "All" assessment scenario is to find a pathway that is optimized to perform well across the range of climate scenarios developed. However, the pathway identified for the "All" scenario does not always (for both sequencing approaches) cater to the worst possible climate. This indicates that if this pathway is selected as the preferred pathway, it may have to be supplemented by additional adaptation actions in the future if the worst possible climate materializes, or may incur some losses due to overbuilding if the future reflects the least extreme scenario. The value of the selection criterion for the "All" climate scenario for both case studies lies within the range of values varying between the least to the most extreme climate scenario. While the pathway identified for the "All" climate scenario does offer a trade-off between the value of the selection criterion and the number of scenarios it can cater to, the final choice of which assessment scenario will dictate the selection of the preferred pathway is case dependent. Selecting the pathway that can cater to the most extreme climate scenario is akin to choosing a robust solution, while selecting the pathway for the all scenario is akin to choosing the pathway that offers the best trade-off between flexibility/cost (depending up the selection criterion) and flood robustness. The choice of the climate assessment scenario is thus dependent upon the level of desired robustness that a solution must offer. In cases wherein there is critical infrastructure such as hospitals, airports, military installations, etc., the need for robustness will be greater than in areas which are primarily playgrounds, forests or areas which house low value infrastructure.

\section{Conclusions}

An adaptation map consists of multiple pathways that provide a very large solution space. Having such a large set of solutions makes it difficult for decision makers to use the adaptation pathway map as is, to guide specific decision on which infrastructure solutions to implement. There is thus a need to further analyze the adaptation pathway maps to identify which action or pathway should be considered for implementation. As the implementation of measures on a large scale require long-term planning, it is important to establish a baseline plan to allow adequate time for implementation of adaptation measures. The identification of this baseline plan is necessary as its understanding can be very beneficial to decision makers, to establish an approximate time scale for adaptation. Given that the further assessment of adaptation pathways to develop a baseline plan requires post processing of the entire adaptation pathway maps developed, currently used informal approaches to aid in the subselection of adaptation pathways are very cumbersome and computationally intensive. This paper aimed to improve the manner in which pathways are shortlisted by presenting two formal sequencing approaches, namely the "Build Up" and the "Build to Target" approaches for pathway subselection. These approaches vary in the degree of flexibility they offer. Each of these approaches used the Net Present Value and the Real Options Analysis as selection criterions. Two case studies, the Kent Ridge and the Waas, were used to exemplify these approaches.

The Build Up approach maximizes the value of the selection criterion for each phase, identifying the adaptation actions for each phase in a sequential manner, while the Build to Target approach identifies the complete pathway that maximizes the value of the selection criterion for the entire planning horizon. Thus, it is intuitive that the Build $\mathrm{Up}$ approach is more flexible and responsive to a changing scenario. However, it results in plans with less favorable selection criterion values when compared to plans selected by the Build to Target approach. When comparing the pathways that resulted from the analysis of both of these approaches it was observed that the Build to Target 
approach shortlisted pathways that carried a selection criterion value that was higher (or at least the same) than the value of pathways outlined by the Build Up approach. Given the characteristic of the Adaptation Pathway map to cater to uncertainties, it is thus recommended that the Built to Target approach be used to outline and shortlist adaptation pathways from a given adaptation pathway map.

The NPV and the Real Options valuation were used as the selection criterion to shortlist pathways by each approach. Given the real option analysis is able to capture the value of managerial flexibility to respond to uncertainty, this paper makes the case of using the real options value as the selection criterion of choice when faced with making investment decision under uncertainty. When comparing the value of the two criterions, we can see that the maximization of one criterion can only be achieved at the compromise of the second. The fact that a higher Real Options Value is accompanied by a drop in the NPV criterion value quantifies the notion that increasing flexibility comes at a cost.

This paper focused on maximizing the value of a single economic criterion, either the NPV or the Real Options value, to enable the sub-selection of the preferred pathway. However, given the nature of the problem, it may not appropriate to use a single criterion to justify the choice of the plan used to combat uncertainty. This notion can be addressed further in future studies by exploring the use of multiple objective genetic optimization in designing and subselecting adaptation pathways.

Supplementary Materials: The following are available online at www.mdpi.com/2073-4441/10/2/229/s1, Figure S1: Adaptation Tipping Points of Adaptation Actions. Please refer to Table 1 in the main paper for the key of action portfolios, Figure S2: Adaptation Tipping Points for the Waas Case, Table S1: Climate Scenarios, Kent Ridge Case Study, Table S2: Land Use Scenarios, Kent Ridge Case Study, Table S3: Results BTT sequencing approach using ROA as selection criterion, Kent Ridge Catchment., Table S4: Results BU sequencing approach using ROA as selection criterion, Kent Ridge Catchment., Table S5: Results BTT sequencing approach using NPV as selection criterion, Kent Ridge Catchment, Table S6: Results BTT sequencing approach using NPV as selection criterion, Kent Ridge Catchment., Table S7: Results BTT sequencing approach using ROA as selection criterion, Waas Case, Table S8: Results BU sequencing approach using ROA as selection criterion, Waas Case, Table S9: Results BTT sequencing approach using NPV as selection criterion, Waas Case, Table S10: Results BU sequencing approach using NPV as selection criterion, Waas Case.

Author Contributions: Nishtha Manocha and Vladan Babovic conceived the idea of applying sequencing approaches to aid pathway sub-selection. Nishtha Manocha performed the sequencing approaches and analysed the results. Nishtha Manocha wrote the paper which was reviewed by Vladan Babovic.

Conflicts of Interest: The authors declare no conflict of interest

\section{References}

1. Urich, C.; Rauch, W. Exploring critical pathways for urban water management to identify robust strategies under deep uncertainties. Water Res. 2014, 66, 374-389. [CrossRef] [PubMed]

2. Chang, N.-B.; Qi, C.; Yang, Y.J. Optimal expansion of a drinking water infrastructure system with respect to carbon footprint, cost-effectiveness and water demand. J. Environ. Manag. 2012, 110, 194-206. [CrossRef] [PubMed]

3. Dewar, J.A. Assumption-Based Planning: A Tool for Reducing Avoidable Surprises; Cambridge University Press: New York, NY, USA, 2002.

4. Dewar, J.A.; Builder, C.H.; Hix, W.M.; Levin, M.H. Assumption-Based Planning; A Planning Tool for very Uncertain Times; Rand Corp.: Santa Monica, CA, USA, 1993.

5. Lempert, R.J.; Popper, S.W.; Bankes, S.C. Shaping the next one Hundred Years: New Methods for Quantitative, Long-Term Policy Analysis and Bibliography; Rand Corp.: Santa Monica, CA, USA, 2003.

6. Groves, D.G.; Lempert, R.J. A new analytic method for finding policy-relevant scenarios. Glob. Environ. Chang. 2007, 17, 73-85. [CrossRef]

7. Ranger, N.; Reeder, T.; Lowe, J. Addressing 'deep' uncertainty over long-term climate in major infrastructure projects: four innovations of the Thames Estuary 2100 Project. EURO J. Decis. Process. 2013, 1, $233-262$. [CrossRef]

8. Walker, W.; Haasnoot, M.; Kwakkel, J. Adapt or Perish: A Review of Planning Approaches for Adaptation under Deep Uncertainty. Sustainability 2013, 5, 955-979. [CrossRef]

9. Walker, W.E.; Rahman, S.A.; Cave, J. Adaptive policies, policy analysis, and policy-making. Eur. J. Oper. Res. 2001, 128, 282-289. [CrossRef] 
10. Reeder, T.; Ranger, N. How Do You Adapt in an Uncertain World? Lessons from the Thames Estuary 2100 Project; World Resources Institute: Washington, DC, USA, 2011.

11. Haasnoot, M.; Middelkoop, H.; Offermans, A.; Van Beek, E.; Van Deursen, W.P. Exploring pathways for sustainable water management in river deltas in a changing environment. Clim. Chang. 2012, 115, 795-819. [CrossRef]

12. Kwadijk, J.C.J.; Haasnoot, M.; Mulder, J.P.M.; Hoogvliet, M.M.C.; Jeuken, A.B.M.; van der Krogt, R.A.A.; van Oostrom, N.G.C.; Schelfhout, H.A.; van Velzen, E.H.; van Waveren, H.; et al. Using adaptation tipping points to prepare for climate change and sea level rise: A case study in the Netherlands. Wiley Interdiscip. Rev. Clim. Chang. 2010, 1, 729-740. [CrossRef]

13. Haasnoot, M.; Middelkoop, H.; van Beek, E.; van Deursen, W.P.A. A method to develop sustainable water management strategies for an uncertain future. Sustain. Dev. 2011, 19, 369-381. [CrossRef]

14. Haasnoot, M.; Kwakkel, J.H.; Walker, W.E.; ter Maat, J. Dynamic adaptive policy pathways: A method for crafting robust decisions for a deeply uncertain world. Glob. Environ. Chang. 2013, 23, 485-498. [CrossRef]

15. Kwakkel, J.H.; Haasnoot, M.; Walker, W.E. Developing dynamic adaptive policy pathways: A computer-assisted approach for developing adaptive strategies for a deeply uncertain world. Clim. Chang. 2014, 132, 373-386. [CrossRef]

16. Zischg, J.; Goncalves, M.L.; Bacchin, T.K.; Leonhardt, G.; Viklander, M.; van Timmeren, A.; Rauch, W.; Sitzenfrei, R. Info-Gap robustness pathway method for transitioning of urban drainage systems under deep uncertainties. Water Sci. Technol. 2017, 76, 1272. [CrossRef] [PubMed]

17. Zhang, S.X.; Babovic, V. A real options approach to the design and architecture of water supply systems using innovative water technologies under uncertainty. J. Hydroinform. 2012, 14, 13. [CrossRef]

18. Gersonius, B.; Ashley, R.; Pathirana, A.; Zevenbergen, C. Climate change uncertainty: Building flexibility into water and flood risk infrastructure. Clim. Chang. 2012, 116, 411-423. [CrossRef]

19. Hu, J.; Cardin, M.-A. Generating flexibility in the design of engineering systems to enable better sustainability and lifecycle performance. Res. Eng. Des. 2015, 26, 121-143. [CrossRef]

20. Deng, Y.; Cardin, M.-A.; Babovic, V.; Santhanakrishnan, D.; Schmitter, P.; Meshgi, A. Valuing flexibilities in the design of urban water management systems. Water Res. 2013, 47, 7162-7174. [CrossRef] [PubMed]

21. Swart, R.J.; Raskin, P.; Robinson, J. The problem of the future: Sustainability science and scenario analysis. Glob. Environ. Chang. 2004, 14, 137-146. [CrossRef]

22. Bankes, S. Exploratory modeling for policy analysis. Oper. Res. 1993, 41, 435-449. [CrossRef]

23. Korteling, B.; Dessai, S.; Kapelan, Z. Using information-gap decision theory for water resources planning under severe uncertainty. Water Resour. Manag. 2013, 27, 1149-1172. [CrossRef]

24. Butcher, W.S.; Haimes, Y.Y.; Hall, W.A. Dynamic programing for the optimal sequencing of water supply projects. Water Resour. Res. 1969, 5, 1196-1204. [CrossRef]

25. Becker, L.; Yeh, W.W.G. Optimal timing, sequencing, and sizing of multiple reservoir surface water supply facilities. Water Resour. Res. 1974, 10, 57-62. [CrossRef]

26. Braga, B.P.F.; Conejo, J.G.L.; Becker, L.; Yeh, W.W.-G. Capacity expansion of Sao Paulo water supply. J. Water Resour. Plan. Manag. 1985, 111, 238-252. [CrossRef]

27. Dandy, G.; Connarty, A.M. Interactions between Water Pricing, Demand Management and the Sequencing of Water Resource Projects. In Water down under 94: Groundwater/Surface Hydrology Common Interest Papers; Institution of Engineers: Barton, Australia, 1994.

28. Mulvihill, M.E.; Dracup, J.A. Optimal timing and sizing of a conjunctive urban water supply and waste water system with nonlinear programing. Water Resour. Res. 1974, 10, 170-175. [CrossRef]

29. Rubinstein, J.; Ortolano, L. Water conservation and capacity expansion. J. Water Resour. Plan. Manag. 1984, 110, 220-237. [CrossRef]

30. Martin, Q.W. Hierarchical algorithm for water supply expansion. J. Water Resour. Plan. Manag 1987, 113, 677-695. [CrossRef]

31. Manocha, N.; Babovic, V. Planning Flood Risk Infrastructure Development under Climate Change Uncertainty. Procedia Eng. 2016, 154, 1406-1413. [CrossRef]

32. Dixit, A.K.; Pindyck, R.S. The Options Approach to Capital Investment; Harvard Business School Press: Boston, MA, USA, 1995; p. 105.

33. Buurman, J.; Zhang, S.; Babovic, V. Reducing risk through real options in systems design: The case of architecting a maritime domain protection system. Risk Anal. 2009, 29, 366-379. [CrossRef] [PubMed] 
34. Zhang, S.X.; Babovic, V. An evolutionary real options framework for the design and management of projects and systems with complex real options and exercising conditions. Decis. Support Syst. 2011, 51, 119-129. [CrossRef]

35. De Neufville, R.; Scholtes, S.; Wang, T. Real Options by Spreadsheet Parking Garage. J. Infrastruct. Syst. 2006, 12, 107-111. [CrossRef]

36. Woodward, M.; Kapelan, Z.; Gouldby, B. Adaptive Flood Risk Management under Climate Change Uncertainty Using Real Options and Optimization. Risk Anal. 2014, 34, 75-92. [CrossRef] [PubMed]

37. Buurman, J.; Babovic, V. Adaptation Pathways and Real Options Analysis: An approach to deep uncertainty in climate change adaptation policies. Policy Soc. 2016, 35, 137-150. [CrossRef]

38. Dandy, G.; Kolokas, L.; Frey, J.; Gransbury, J.; Duncker, A.; Murphy, L. Optimal staging of capital works for large water distribution systems. In Proceedings of the ASCE Conference on Water Resources Planning and Management, Roanoke, VA, USA, 19-22 May 2002.

39. Manocha, N.; Babovic, V. Development and valuation of adaptation pathways for storm water management infrastructure. Environ. Sci. Policy 2017, 77, 86-97. [CrossRef]

40. Myers, S.C. Finance Theory and Financial Strategy. Interfaces 1984, 14, 126-137. [CrossRef]

41. Beh, E.H.Y.; Dandy, G.C.; Maier, H.R.; Paton, F.L. Optimal sequencing of water supply options at the regional scale incorporating alternative water supply sources and multiple objectives. Environ. Model. Softw. 2014, 53, 137-153. [CrossRef]

42. Van den Hurk, B.; Tank, A.K.; Lenderink, G.; van Ulden, A.; van Oldenborgh, G.J.; Katsman, C.; van den Brink, H.; Keller, F.; Bessembinder, J.; Burgers, G.; et al. New climate change scenarios for the Netherlands. Water Sci. Technol. 2007, 56, 27-33. [CrossRef] [PubMed]

(C) 2018 by the authors. Licensee MDPI, Basel, Switzerland. This article is an open access article distributed under the terms and conditions of the Creative Commons Attribution (CC BY) license (http:/ / creativecommons.org/licenses/by/4.0/). 